\title{
Assessment of Personnel Actions in the Most Dangerous Accidents
}

\author{
Maria Berberova ${ }^{1,2,3, *}$ \\ ${ }^{1}$ ANO HE "Russian New University", Moscow, Russia Federation \\ ${ }^{2}$ ANO International Nuclear Safety Center, Moscow, Russia Federation \\ ${ }^{3}$ ANO "Scientific and Research Center for Information in Physics and Technique", Nizhny Novgorod, Russia Federation
}

\begin{abstract}
The reliability of the human operator is an essential indicator of the safe operation of nuclear power plants. Mistakes can be made during performance checks, maintenance, at the stage of accident management, etc. A number of different factors affect the stability of a nuclear power plant: level of organization of the project, quality of equipment in operation, selection and training of competent personnel, maintaining the qualifications of NPP workers, and etc. In the "man-machine" system, the reliability of the technical component is calculated by known methods and in accordance with established reliability standards. However, the "human" component cannot be technically and accurately determined, therefore, it is necessary to undertake systematic efforts to increase and subsequently maintain the achieved level of reliability of this component. The contribution of the human factor to emergencies at technosphere facilities is significant: $70 \%$ of air crashes, $50 \%$ of disasters in the fleet occur precisely due to incorrect actions (low reliability) of personnel. According to statistics, the main causes of accidents are improper actions (low reliability) of personnel (60-70\%), technical reasons (20-30\%), adverse effects of external factors, etc.
\end{abstract}

Keywords. personnel, the most dangerous (beyond design basis) accidents, personnel reliability, stress, normal operation, emergency.

\section{Introduction}

Since 1997 (since the approval of OPB88 / 97 (replaced by the Federal Norms and Rules in the Field of Atomic Energy Use "General Provisions for Ensuring the Safety of Nuclear Power Plants" (NP-001-15) [1])), at all Russian NPPs Probabilistic Safety Analysis (PSA) has become mandatory. In November 2004, Order No. 506 [2] was signed at the Russian Emergencies Ministry, according to which a standard safety data sheet for a hazardous facility was further developed. To fill out section II of the safety data sheet [3], it is necessary to carry out a risk assessment of the objects in question. The problem of evaluating the risk indicators of especially dangerous objects (in particular, nuclear power plants) is devoted to the works of both domestic ([4-8 and others]) and foreign scientists ([9-13 and others]). However, the vast majority of studies in this area are devoted to such problems as: physics and kinetics of nuclear reactors; reliability theory; safety analysis; risk assessment. Tasks like assessment of the reliability of personnel under psychological stress in the writings of these authors have not been investigated..

In 2015, the work "Assessment of risk indicators for the second phases of Smolensk and Kursk NPPs" [14] was published. In [14] such methodological approaches like a methodological approach for calculating the doses of external and internal irradiation of the population in the ring segment of the rumba and a methodical approach for assessing damage to the population in the ring segment of the rumba due to exposure to radioactive substances. However, the tasks of estimating the doses of external and internal radiation and the damage to the population (taking into account the age composition of the population) living around nuclear power plants during the most dangerous (beyond design) accidents involving the emission of thermal neutron sources with a low flux density were not studied in this work either.

In mid-2017, work began on the study of the dependence of the results of assessments of the radiation risk of nuclear power plants on the composition of the population living around nuclear power plants $[15,16]$. But even these works do not address the issues of personnel reliability under psychological stress.

\section{Personnel reliability analysis under psychological stress}

According to [17], psychological stress is a reaction to the characteristics of the interaction between a person and the surrounding world. The state of stress is mainly a consequence of personal cognitive processes, a way of thinking and assessing a situation, knowing one's own

Corresponding author: maria.berberova@gmail.com 
abilities (resources), the degree of training in management methods and behavioral strategies in extreme conditions, and their adequate choice.

Factors that determine the stressfulness of an event:

- emotions that are associated with this event;

- the uncertainty of the situation associated with the lack of information for its assessment;

- the significance of the event, reflecting the degree of its danger to a person or others;

- importance to achieve the end result.

Phases of the physiological adaptation process under stress [18]:

1) Initial adaptation. This phase develops at the very beginning of the action (physiological or pathogenic factors); consists of two multidirectional complexes of reactions:

- An indicative reflex (accompanied by inhibition of many types of activities carried out up to this time).

- Activation of neuro-trophic influence (stores and provides the body with the necessary energy).

The initial phase of adaptation can be expressed in different ways, depending on the strength of the annoying factors (the stronger they are, the more pronounced this phase). Accordingly, it can be accompanied by a strongly or weakly expressed emotional component.

2) Transition phase. During this phase, the adaptive mechanisms of the body gradually switch to a deeper cell level. These shifts provide a new level of homeostasis. The nonspecific resistance of the organism increases, and at the same time, various mechanisms of specific adaptation develop.

3) Sustainable adaptation. It is of a long-term nature, the basis of the prerequisites for the development of this phase are memory mechanisms in the central nervous system. Control mechanisms are coordinated. A characteristic feature of life in the phase of sustainable adaptation is the relative profitability ("turning off unnecessary reactions") of energy costs to maintain it. Switching the body's reactivity to a new level is accompanied by both the mobilization of a number of reactions and the return of the activity of auxiliary systems to the initial indicators.

4) The phase of disadaptation. This condition can occur as a result of depletion of physiological reserves and a violation of the interaction of regulatory and metabolic adaptation mechanisms. As a result, the body disrupts the balance of consumption and recovery in organs and tissues, as well as the relationship in the work of physiological systems. Once again, auxiliary systems come to a state of increased activity - respiration and blood circulation; energy in the body is not spent economically. Disadaptation occurs most often in cases where the functional activity in the new conditions is excessive or the action of factors that were the main stimulants of adaptive changes in the body increases, and they approach extreme strengths.

\section{Comparison and analysis of data obtained under normal use and in an emergency}

The study was conducted on the basis of data obtained from the simulator of the Novovoronezh NPP based on a survey of 30 operators [19]. The survey of operators was depersonalized. The tests were carried out in the afternoon and evening shifts. At this time, as a rule, work is carried out on equipment, bypasses of the management personnel, therefore this period can be considered normal loaded.

Operational personnel account for $55 \%$ of violations of normal operation.

In case of emergency situations, as a rule, a group reorganization of the control room switchboard occurs. There are the following types of group behavior of operators in case of accidents:

- the main operator (supervisor) takes on a leading role, monitors the situation and makes decisions, and the remaining members of the watch carry out his decision;

- the supervisor and other members of the watch work on an equal footing, so it is difficult to identify the decision maker.

The table 1 shows data on the reliability of tasks by operational personnel on the simulator in normal use.

Table 1. Statistical data and reliability indicators for the performance of tasks by operational personnel on the simulator VVER-440 Novovoronezh training center.

\begin{tabular}{|c|c|c|c|c|}
\hline \multirow{2}{*}{ № } & Task characteristics and reliability & \multicolumn{3}{|c|}{ Operator groups } \\
\cline { 3 - 5 } indicators & Interns & $\begin{array}{c}\text { Experienced } \\
\text { operators }\end{array}$ & Together \\
\hline 1 & Number of task types presented & 70 & 37 & 78 \\
\hline 2 & $\begin{array}{c}\text { The number of completed task } \\
\text { implementations }\end{array}$ & 299 & 85 & 489 \\
\hline \multirow{3}{*}{3} & \multicolumn{3}{|c|}{ Of the total number of tasks: } \\
\cline { 2 - 5 } & performed unmistakably & 217 & 49 & 356 \\
\cline { 2 - 5 } & executed with minor errors & 43 & 25 & 75 \\
\cline { 2 - 5 } & failed (failure to execute) & 39 & 11 & 58 \\
\hline
\end{tabular}

According to the main indicators presented in table 1 , we construct the graph shown in Fig. 1. The graph clearly shows that in normal use, the percentage of errorfree operations is high $(72.6 \%$ error-free operations for trainees, $57.6 \%$ - for experienced operators, $72.8 \%$ - for joint tasks)

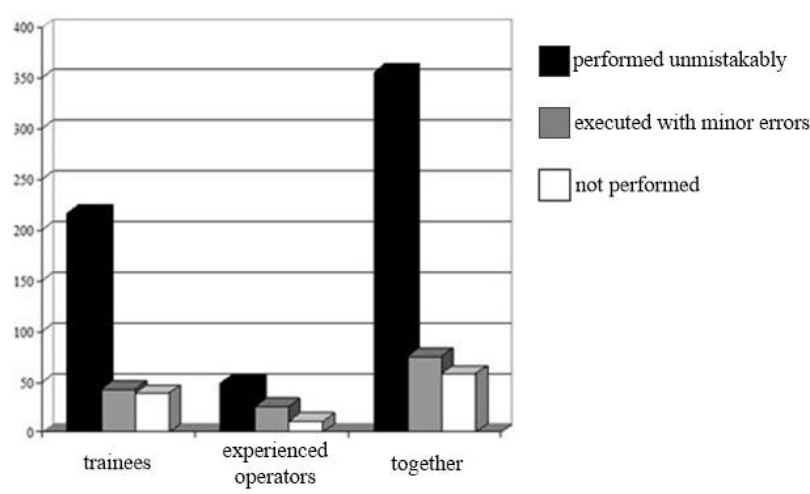

Fig. 1. Schedule of reliability of tasks by operational staff in normal use 
When decisive action is required to solve a nonstandard task with a shortage of time, the situation becomes stressful. The more controversial the situational and target settings, the higher the level of stress experienced.

For example, there is the desire to remove the controlled unit from a dangerous state and the realization that it is impossible to do this for objective, situational reasons or when the employee does not know how to do this in this situation. This is a typical situation preceding a forced shutdown of a reactor when there is not enough time or information to understand what needs to be done to prevent shutdown.

The opposite picture may also occur - the operator knows what is being done in the specific threat of block exit from the given mode, but in the presence of even the smallest risk, he prefers to provide work to an automatic protection system that will stop the block.

The dependence of the effects of stress on the emotional reaction of a person to a stressor indicates the participation of limbic structures in the higher control of the stress response. The decision is made with the participation of the frontal lobes of the brain, which together with the hippocampus provide a person's response to unlikely events.

It is known that in the early stages of adaptation after exposure to stress (up to 4 days) there is an improvement in memorization of emotional stimuli (by $40-50 \%$ ) and memory impairment for neutral stimuli.

On the 11-21 day the state of the body returns to normal. Recollection of neutral information rises. At the same time, the accuracy of playback increases significantly (4-5 times).

Adaptive rearrangements affect the most common mechanisms of the central nervous system, controlling the perception and memorization of any emotional stimuli.

During an emergency, memory impairment due to neutral stimuli is expected. The effects of this reaction are more affected by experienced operators. Their emotional response is lower than that of trainees (since they have been repeatedly affected by severe stress, their body has adapted). They are more likely to trust their experience, but the accuracy of reproducing the information they know is lower. This means that the probability of making minor mistakes increases.

The interns will try to remember an instruction, and complete the task in accordance with it.

Table 2. Statistical data and reliability indicators for performing tasks by operational personnel on the vver-440 simulator of the novovoronezh training center in an emergency

\begin{tabular}{|c|c|c|c|c|}
\hline \multirow{2}{*}{$№$} & \multirow{2}{*}{$\begin{array}{c}\text { Task characteristics and } \\
\text { reliability indicators }\end{array}$} & \multicolumn{3}{|c|}{ Operator groups } \\
\cline { 3 - 5 } & Interns & $\begin{array}{c}\text { Experienced } \\
\text { operators }\end{array}$ & Together \\
\hline 1 & Number of task types presented & 28 & 25 & 28 \\
\hline \multirow{2}{*}{2} & $\begin{array}{c}\text { The number of completed task } \\
\text { implementations }\end{array}$ & 271 & 286 & 697 \\
\hline \multirow{4}{*}{3} & Of the total number of tasks: & & & \\
\cline { 2 - 5 } 3 & performed unmistakably & 158 & 87 & 336 \\
\cline { 2 - 5 } & executed with minor errors & 51 & 153 & 242 \\
\cline { 2 - 5 } & failed (failure to execute) & 62 & 46 & 119 \\
\hline
\end{tabular}

The table 2 shows data on the reliability of tasks by operational personnel on the simulator in an emergency.

According to the main indicators presented in Table 2, we construct the graph shown in Fig. 2. The graph clearly shows that in normal use, the percentage of errorfree operations is high $(58.3 \%$ error-free operations for trainees, $18.8 \%$ - for experienced operators, $22.9 \%$ - for joint tasks).

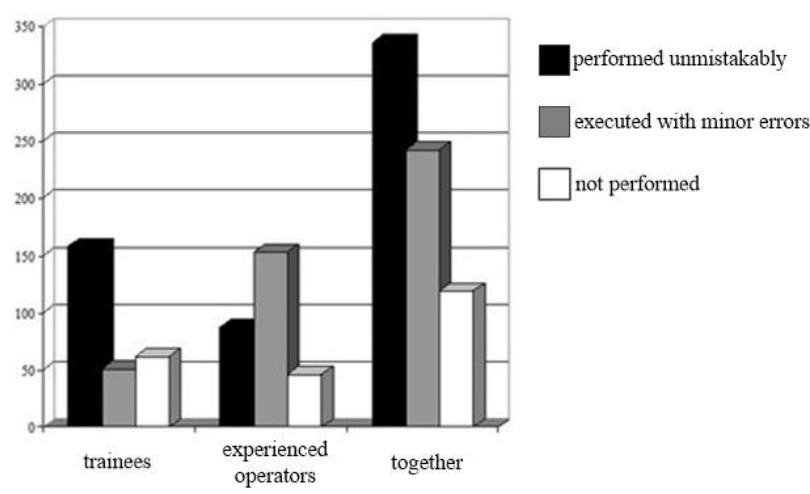

Fig. 2. Schedule of reliability of task performance by operational personnel in an emergency

\section{Results}

The results of this analysis confirm a significant difference in the mistakes made under normal use and under stressful conditions.

Thus, we see that the stress adaptation system can significantly reduce the emotional response of staff. It is this system that is responsible for the development of experience, which helps to increase the efficiency and correctness of decisions made. At the same time, in an emergency situation, the performance of experienced personnel is deteriorating. This is explained precisely by the system of adaptation of the body to stress, since a reduced emotional reaction reduces attentiveness, which leads to the commission of gross errors by the operator.

\section{Conclusion}

In the future it is planned:

1) To continue work on the assessment of personnel actions in the most dangerous (beyond design basis) accidents with the emission of thermal neutron sources with a low flux density.

2) To develop a methodological approach to solving the problems of assessing doses of external and internal irradiation and assessing damage to the population (taking into account the age composition of the population) living around nuclear power plants during the most dangerous (beyond design basis) accidents involving the emission of thermal neutron sources with a low flux density.

To develop an atlas of risk indicator estimates; to develop a program for monitoring (control) the safety of nuclear power plants. 
The reported study was funded by RFBR according to the research projects № 18-07-00225, 18-07-00909, 18-07-01111, 19-07-00455.

\section{References}

1. Federal norms and rules in the field of atomic energy use "General provisions for ensuring the safety of nuclear power plants" (NP-001-15), (2015)

2. On approval of a standard safety data sheet for a hazardous facility, Order of the Russian Ministry for Emergencies, 506 (2004)

3. Safety data sheet of the critical (dangerous) facility of Rosatom, Order of the Russian Ministry for Emergencies, 506 (2004)

4. Yu.A. Kazansky, A.B. Lebedev, Kinetics of nuclear reactors: a training manual, (1990)

5. V.A. Ostreykovsky, The operation of nuclear power plants: a textbook for universities, (1999)

6. V.A. Ostreykovsky, Reliability theory: textbook for high schools, (2003)

7. A.V. Antonov, M.S. Nikulin, Statistical methods in the theory of reliability: a training manual, (2012)

8. O.M. Gulina, Physics and statistical models of resource management of the equipment of the second circuit of nuclear power plants: dissertation for the degree of Doctor of Technical Sciences, (2009)

9. A.D. Swain, H.E. Guttemann, Handbook of Human Reliability Analysis with Emphasis on Nuclear Power Plant Applications, NUREG/CR- 1278, (1983)

10. N. Bixler, R. Haaker, Accident Consequence Analysis (P-301), (2009)

11. C. Spitzer, U. Schmocker, V.N. Dang, Probabilistic Safety Assessment and Management, Springer (2004)

12. D. Sugarman, Proceedings of the Technical Committee Meeting to summarize the achievement of a five year study of impacts and risks of energy systems (methods and data), IAEA-TC-733.7, (2000)

13. A. Markandva, R. Boyd, Valuing the human health effects of routine atmospheric releases from nuclear facilities, (1999)

14. M.A. Berberova, Assessment of risk indicators for the second phases of Smolensk and Kursk NPPs: dissertation for the degree of candidate of technical sciences, (2015)

15. D.A. Marinina, M.A. Berberova, Assessment of the risk of radiation exposure on the population living near the nuclear power plant under consideration with a WWER reactor, taking into account the age composition , Transactions of the International Scientific Conference SCVRT2017, (2017)

16. D.A. Marinina, M.A. Berberova, Investigation of the dependence of the results of radiation risk assessments for nuclear power plants with a VVERtype reactor on the composition of the population living around nuclear power plants (using the example of Rostov and Kalinin NPPs, Proceedings of the CPT2018 International Scientific Conference (2018)

17. V.A. Bodrov, Psychological stress: development and overcoming, (2006)

18. H. Selye, The general adaptation syndrome and the diseases of adaptation. Journal of Clinical Endocrinology, (1946)

19. A.A. Derevyankin, Research, development and application of methods for assessing the reliability of personnel in conducting a probabilistic safety analysis of nuclear plants, (1991). 